\title{
Chemical Synthesis of Bacterial Glycoconjugates in Relation to Their Immunostimulating Activity
}

\author{
Shoichi Kusumoto, Koichi Fukase, Yasuo Suda, and Masato Oikawa \\ Department of Chemistry, Graduate School of Science, Osaka University,
}

\begin{abstract}
Recent synthetic work on typical cell surface glycoconjugates of bacteria which activate the immunological system of higher animals is described. Lipid A, previously proved to be the active entity of lipopolysaccharide of Gram-negative bacteria, was subjected to further study and novel efficient routes were established for its structural analogs and a ${ }^{3} \mathrm{H}$-labeled derivative. Proposed structures of lipoteichoic acids from Gram-positive bacteria were also synthesized to lead to the conclusion that not the major components corresponding to the proposed structures but other minor ones are responsible for the activity.
\end{abstract}

\section{Introduction}

Bacterial cells are covered with a rigid surface structure called cell envelope which is essential for their survival. The cell envelope is composed of a multi-layer of complex glycoconjugates having unique constituents and structures different from those found in higher animals. When infection of bacteria occurs, the defensive cells of animals such as macrophages and lymphocytes start their action and produce mediator cytokines such as interleukins, interferons, and tumor necrotizing factors to enhance the entire defense system. Interestingly, however, not entire living cells of bacteria are required to activate such defense mechanism but certain typical cell surface glycoconjugates are able to take on the role of the living bacteria. It was further demonstrated that certain definite chemical entities corresponding to partial structures of the glycoconjugates possess the activity.

The first example identified as an "active principle" of cell surface glycoconjugates was Nacetylmuramyl-L-alanyl-D-isoglutamine (so-called muramyl dipeptide, MDP) described by two independent research groups including ourselves (ref. 1). The muramyl peptide is a common buildingblock of cell wall peptidoglycan. This particular molecular species with molecular weight of only around 500 exhibits the definite immunostimulating activity similar to that of the cell wall itself. This result encouraged us to continue our study on other biologically important bacterial glycoconjugates in order to identify the active structures responsible for their immunostimulation and to disclose the mechanism of their action. From the viewpoint of synthetic organic chemistry, these molecules present highly challenging targets. Because of their complex chemical structures and amphiphilic natures difficult to handle, they have never been regarded as direct targets of systematic synthetic work until recently.

In this paper we describe our synthetic work on two typical glycoconjugates, i.e., lipopolysaccharide and lipoteichoic acid, which are typical of gram-negative and positive bacteria, respectively.

\section{Synthesis of lipid A, the lipid component of lipopolysaccharide}

\subsection{Occurrence, biological function and structure of lipid A}


Lipopolysaccharide (LPS) is the chemical entity of bacterial endotoxin which was first described more than a hundred years ago as a heat-stable toxin firmly bound to the cells of Gram-negative organism. As the name endotoxin implies, LPS exhibits various detrimental activities such as lethal toxicity, pyrogenicity, and tissue-damaging activity, which sometimes cause serious clinical problems even today. Simultaneously, however, it also shows a wide range of beneficial activities related to stimulation of immunological responses. LPS is composed of a hydrophilic polysaccharide chain covalently bound to a glycolipid. The latter glycolipid, designated lipid A, was found to be responsible for both beneficial and toxic functions of LPS (ref. 2). The chemical structure of lipid A isolated from Escherichia coli Re mutant was deduced as 1 by our chemical and spectroscopic studies (ref. 3).

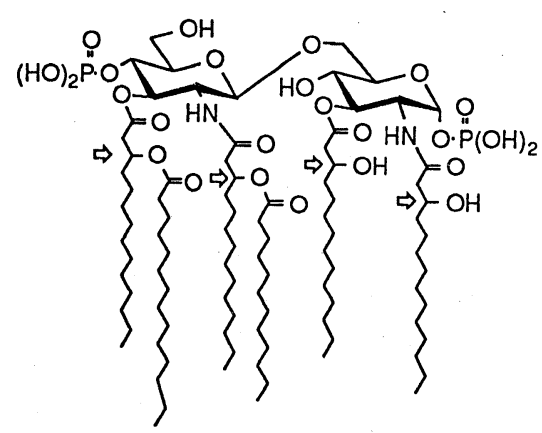

E. coli lipid A $1 \Rightarrow$ : (R)-configuration $3 \Rightarrow:(S)$-configuration

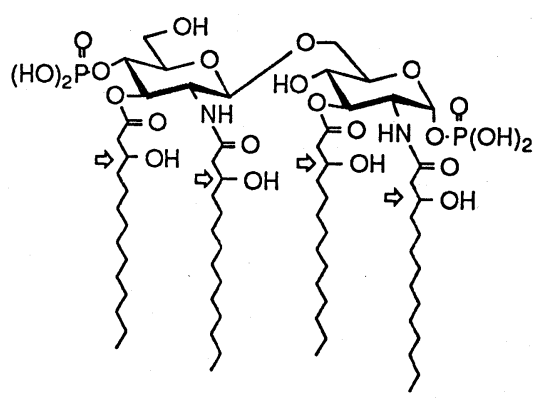

precursor la $2 \Rightarrow:(R)$-configuration

$4 \Rightarrow:(S)$-configuration

\subsection{Synthesis of lipid $A$ and its analogs}

The above proposed structure of lipid A (1) was soon confirmed by our total synthesis starting from D-glucosamine as shown in the scheme below (ref. 4). Synthetic lipid A showed identical biological activities to those of the natural counterpart isolated from bacterial cells (ref. 5).

Various structural analogues of $E$. coli lipid A (1) were isolated from cells of other Gram-negative bacteria. Some of them were also synthesized by similar routes and tested for their activities (ref. 6). Among them, a biosynthetic precursor of lipid A designated precursor Ia (2), which lacks the two nonhydroxylated fatty acids present in 1 , was found to act as an antagonist to 1 , suppressing the cytokine-inducing activity of the latter (ref. 7). For further study on this biologically important glycoconjugate, more efficient synthetic methods for various structural analogues were hence strongly
required.

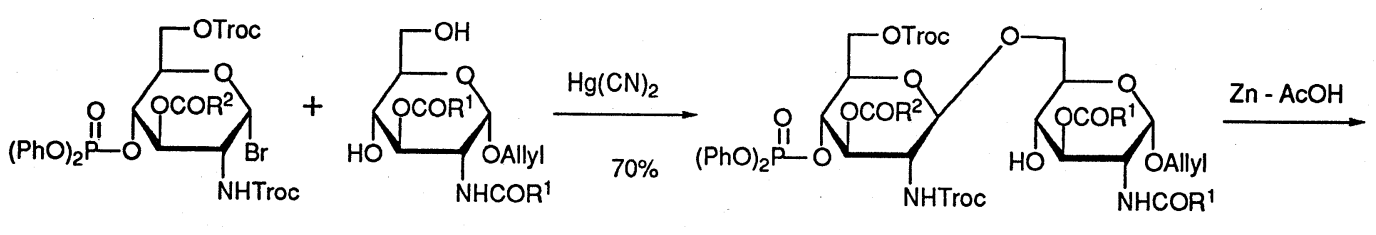

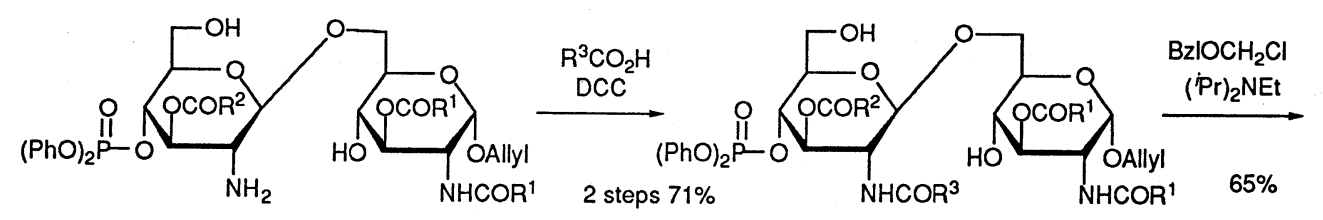



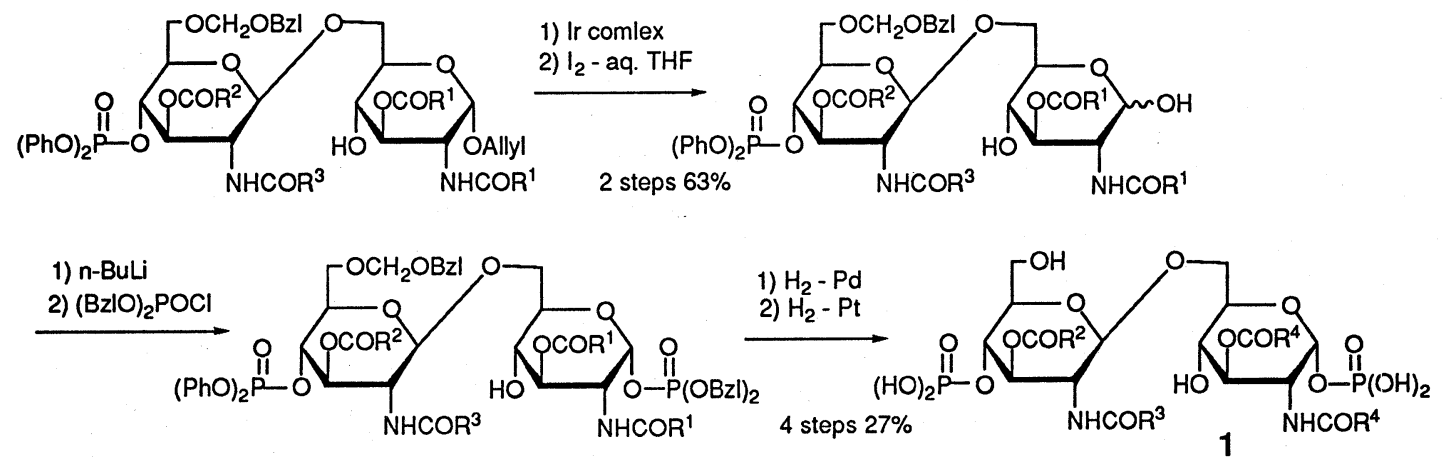

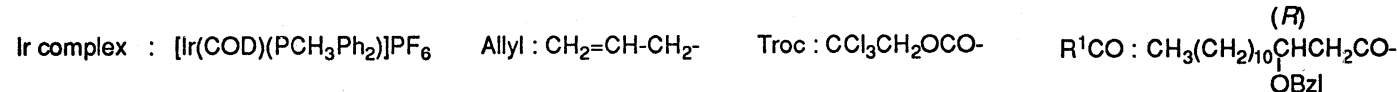
$(R) \quad(R) \quad(R)$
$\begin{array}{ccc}\mathrm{R}^{2} \mathrm{CO}: \mathrm{CH}_{3}\left(\mathrm{CH}_{2}\right)_{10} \mathrm{CHCH}_{2} \mathrm{CO}- & \mathrm{R}^{3} \mathrm{CO}: \mathrm{CH}_{3}\left(\mathrm{CH}_{2}\right)_{10} \mathrm{CHCH}_{2} \mathrm{CO}- & \mathrm{R}^{4} \mathrm{CO}: \mathrm{CH}_{3}\left(\mathrm{CH}_{2}\right)_{10} \mathrm{CHCH}_{2} \mathrm{CO}- \\ \mathrm{CH}_{3}\left(\mathrm{CH}_{2}\right)_{12} \mathrm{COO} & \mathrm{CH}_{3}\left(\mathrm{CH}_{2}\right)_{10} \mathrm{COO} & \mathrm{OH}\end{array}$

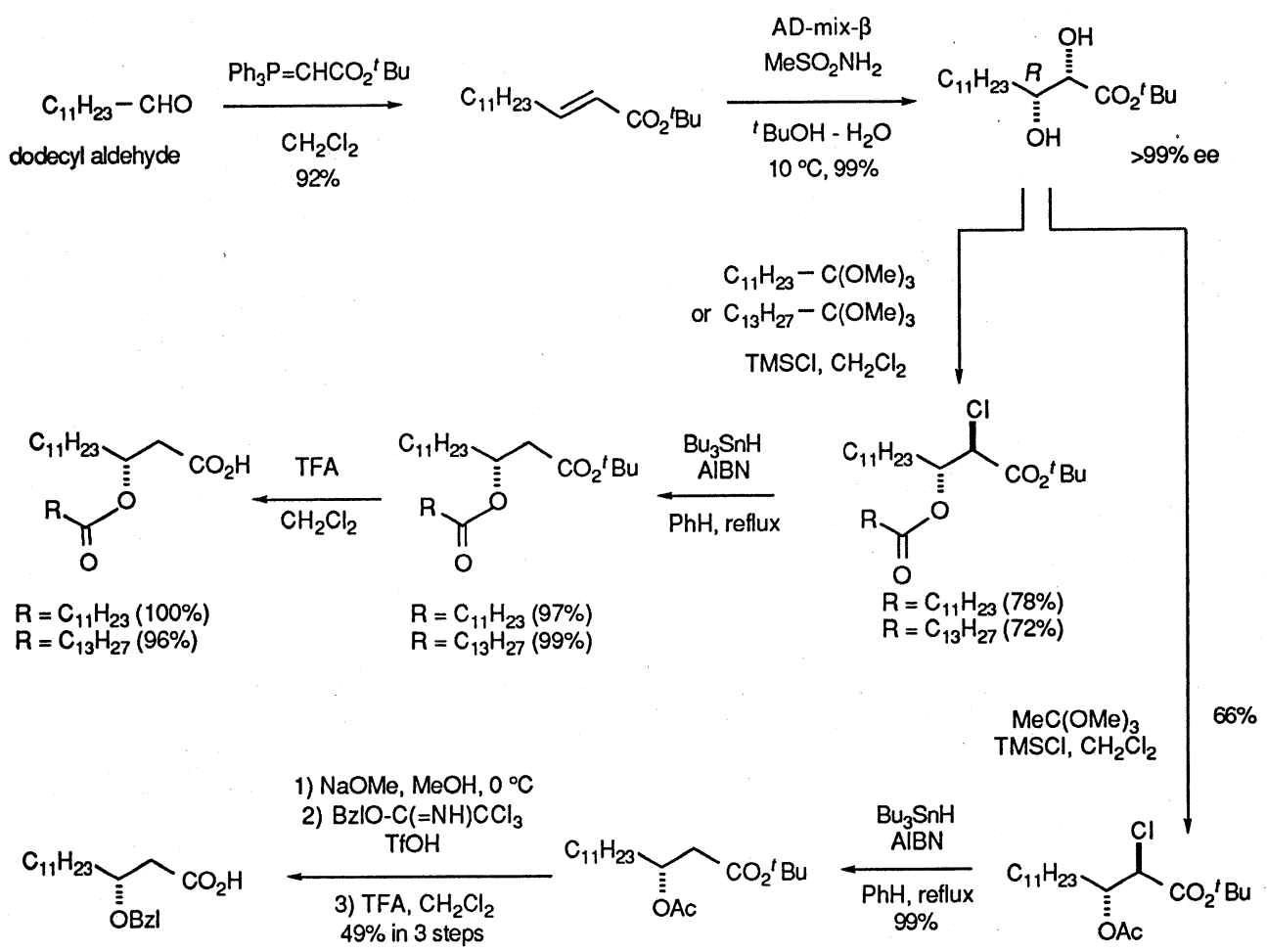

Lipid A contains 3-hydroxy fatty acids (mainly 3-hydroxytetradecanoic acid in the case of $E$. coli) of $R$-configuration, which were prepared in our previous work by asymmetric reduction of the corresponding 3-keto ester with Raney-Ni modified with $(R, R)$-tartaric acid (ref. 8). We then investigated other efficient preparative procedures for both enantiomers of the acid. A new route based on the asymmetric dihydroxylation according to Sharpless is shown in the scheme above (ref. 9). One of the merits of this route, in which no 3-keto acid is used as the key intermediate, is that 3- 
acyloxytetradecanoic acids can be prepared directly. Both enantiomers of 3-hydroxytetradecanoic acid were prepared by lipase-catalyzed asymmetric acetylation of the racemic hydroxy ester obtained by $\mathrm{NaBH}_{4}$-reduction of the 3-keto acid methyl ester (ref. 10). Asymmetric reduction of the 3-keto ester with BINAP-ruthenium catalyst (ref. 11) is a highly efficient route: a high yield (97\%) of either enantiomer ( $>99 \%$ ee) was obtained in one step (at $60^{\circ} \mathrm{C}, 90 \mathrm{~kg} \mathrm{~cm}^{-2}$ ).

A novel efficient synthetic route to lipid A analogues was recently established as exemplified in the scheme below. The scheme illustrates preparation of an artificial analog 4 corresponding to precursor Ia with four moles of (S)-3-hydroxytetradecanoic acid (ref. 10). The $\beta(1-6)$ glycosidic linkage was formed by the imidate method assisted by the participation of the neighboring $N$-Troc group. The use of this glycosidation method in place of the previous one with glycosyl bromide enabled the protection of the distal phosphate group as an o-xylidene ester (ref. 12). This cyclic benzyl type protecting group was removed later smoothly by hydrogenolysis together with all the other benzyl groups in one step (ref. 13). After introduction of the glycosyl phosphate group, the protected final product 5 was carefully purified, which was essentially important to obtain a high yield of the final product by hydrogenolysis. The free lipid A was purified by centrifugal partition chromatography with a solvent system 1-butanol $\mathrm{THF}-\mathrm{H}_{2} \mathrm{O}(9: 7: 20)$ (ref. 10). The procedure is applicable with some minor modifications to the synthesis of various structural analogues of lipid A (ref. 14).
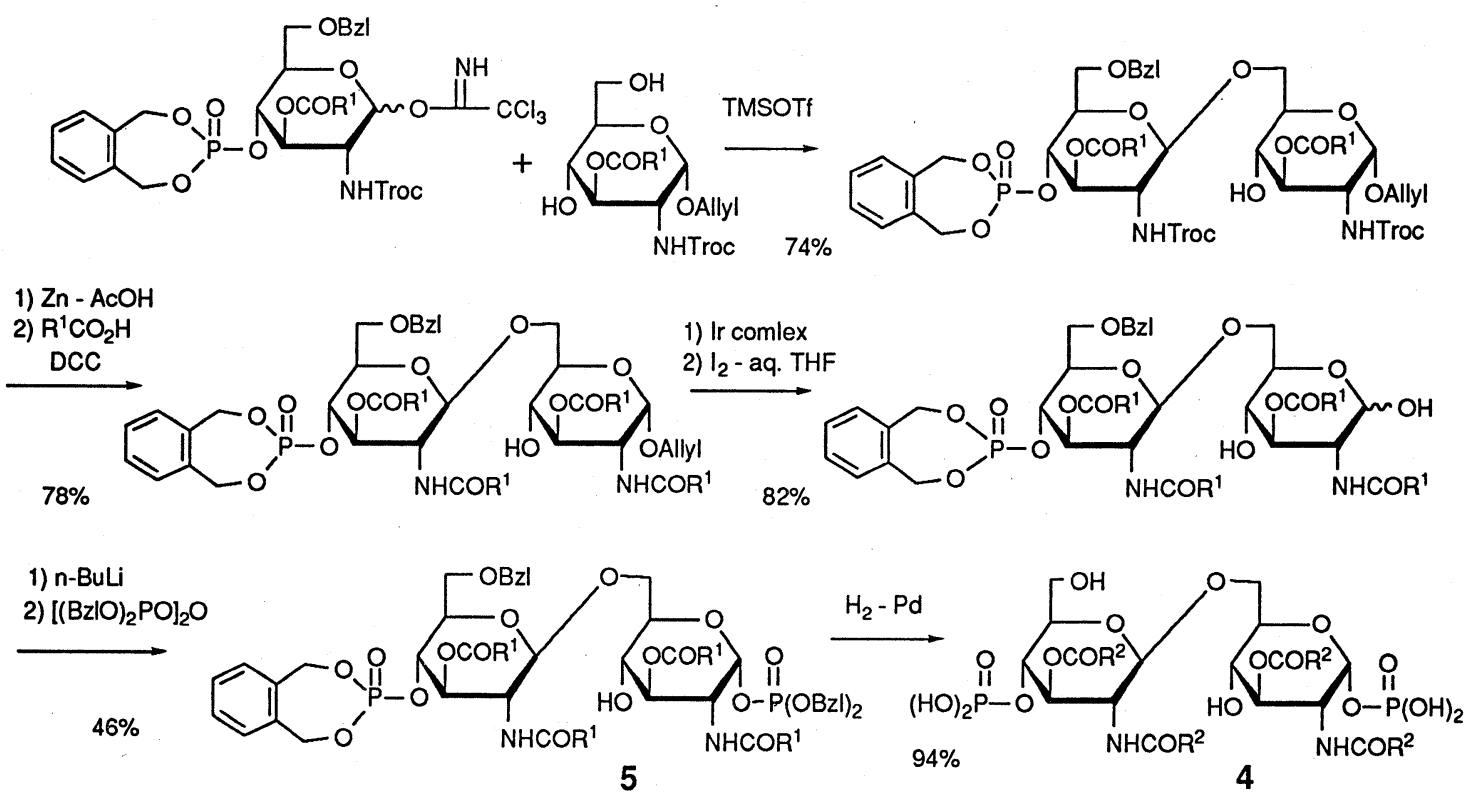

$\mathrm{R}^{1} \mathrm{CO}: \mathrm{OH}_{3}\left(\mathrm{CH}_{2}\right)_{1 \sigma}^{(\mathrm{S})} \underset{\mathrm{OBz}}{\mathrm{CHCH}} \mathrm{H}_{2} \mathrm{CO}$

(S)

$\mathrm{R}^{2} \mathrm{CO}: \mathrm{CH}_{3}\left(\mathrm{CH}_{2}\right)_{10} \sigma \mathrm{C} \mathrm{HCH}_{2} \mathrm{CO}-$

Biological tests of the synthetic compounds revealed the following interesting phenomena. Though the number of acyl groups in the molecule is important for the nature of the activity as mentioned above, the configuration of the fatty acid part has no essential effect. The unnatural analog 3 with (S)-3hydroxy acids exhibited almost the same endotoxic activity as the natural type $E$. coli lipid A (1) with $(R)$-acids. The precursor-type 4 with $(S)$-acids exhibited similar but even stronger antagonistic activity than the natural precursor Ia (2) (ref. 10,14). These observations strongly support the idea that the hydrophilic phosphorylated disaccharide part is important for the biological function of lipid A.

\subsection{Synthesis of radio-labeled lipid A analogues}

Chemical synthesis has another obvious advantage that one can prepare suitably labeled derivatives of lipid A which are expected to be important tools for the investigation of binding proteins and the mode 
of biological action. We next attempted to incorporate radioactivity to the molecule of phosphonooxyethyl analogues (6 and 7) of lipid A (ref. 15). In these artificial compounds one of the phosphate groups of lipid A is bound not directly to the glycosidic hydroxyl group but through an $\alpha-$ glycosidically linked ethylene glycol moiety. Because of this modification which eliminates the chemically labile glycosyl phosphate moiety, the phosphonooxyethyl analogues are stable enough so that their preparation was much easier than the corresponding natural lipid A. In fact, 6 was obtained through short-step transformations as illustrated and purified readily by simple ion-exchange chromatography (ref. 15). Nevertheless, such modification was found to retain the biological activity of lipid A. The phosphonooxyethyl analogues 6 and 7 showed indistinguishable activity from those of 1 and 2, respectively: 6 was endotoxic while 7 was antagonistic.
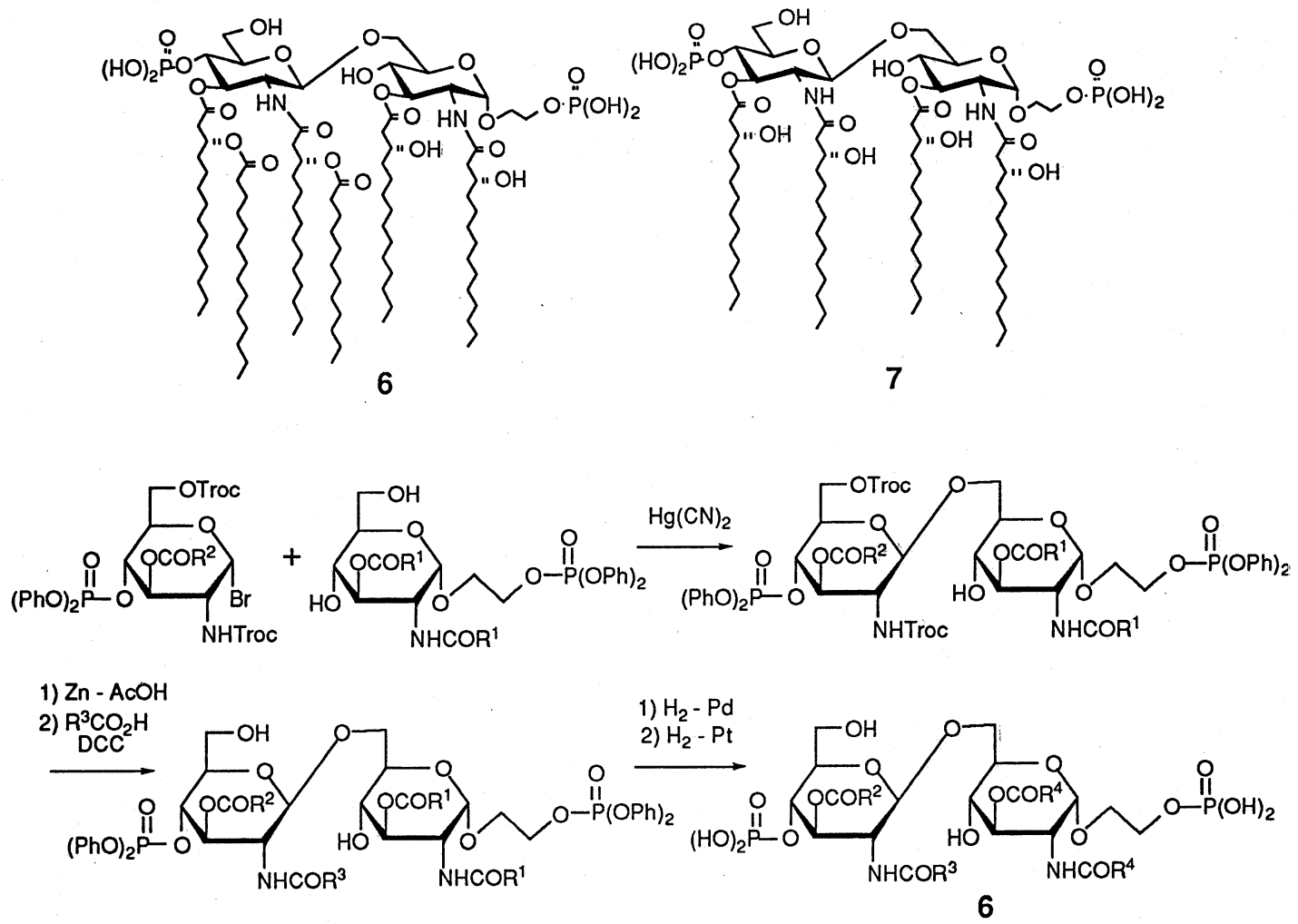

$($ ( )

(R)

(R)

$(R)$

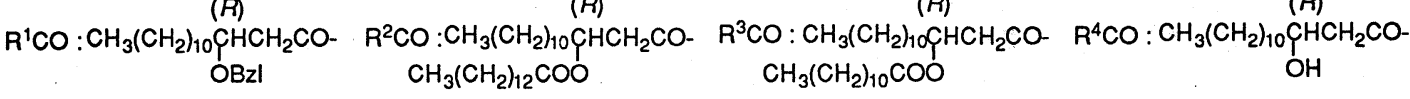

These phosphonooxyethyl analogues, therefore, seemed to be ideal targets of the synthesis of radio-labeled derivatives. We attempted to introduce radioactivity at the ethylene glycol unit of these molecules. A new synthetic route was required, however, for this purpose in order to minimize the number of reaction steps after labeling. An entirely new route was exploited for a tritium-labeled 6 as illustrated in the scheme below by employing a similar strategy to that for the synthesis of 4 above. A disaccharide intermediate 8 was prepared which contains all the acyl groups and 4'-phosphate as well as the glycosidically bound ethylene glycol. A tritium was incorporated to the distal hydroxylmethylene group by $\mathrm{NaB}^{3} \mathrm{H}_{4}$-reduction of the corresponding aldehyde derivative. Phosphorylation followed by HPLC purification and hydrogenolytic deprotection afforded tritium-labeled 6 (ref. 16). A similar procedure is being applied to the synthesis of antagonistic analog 7. 

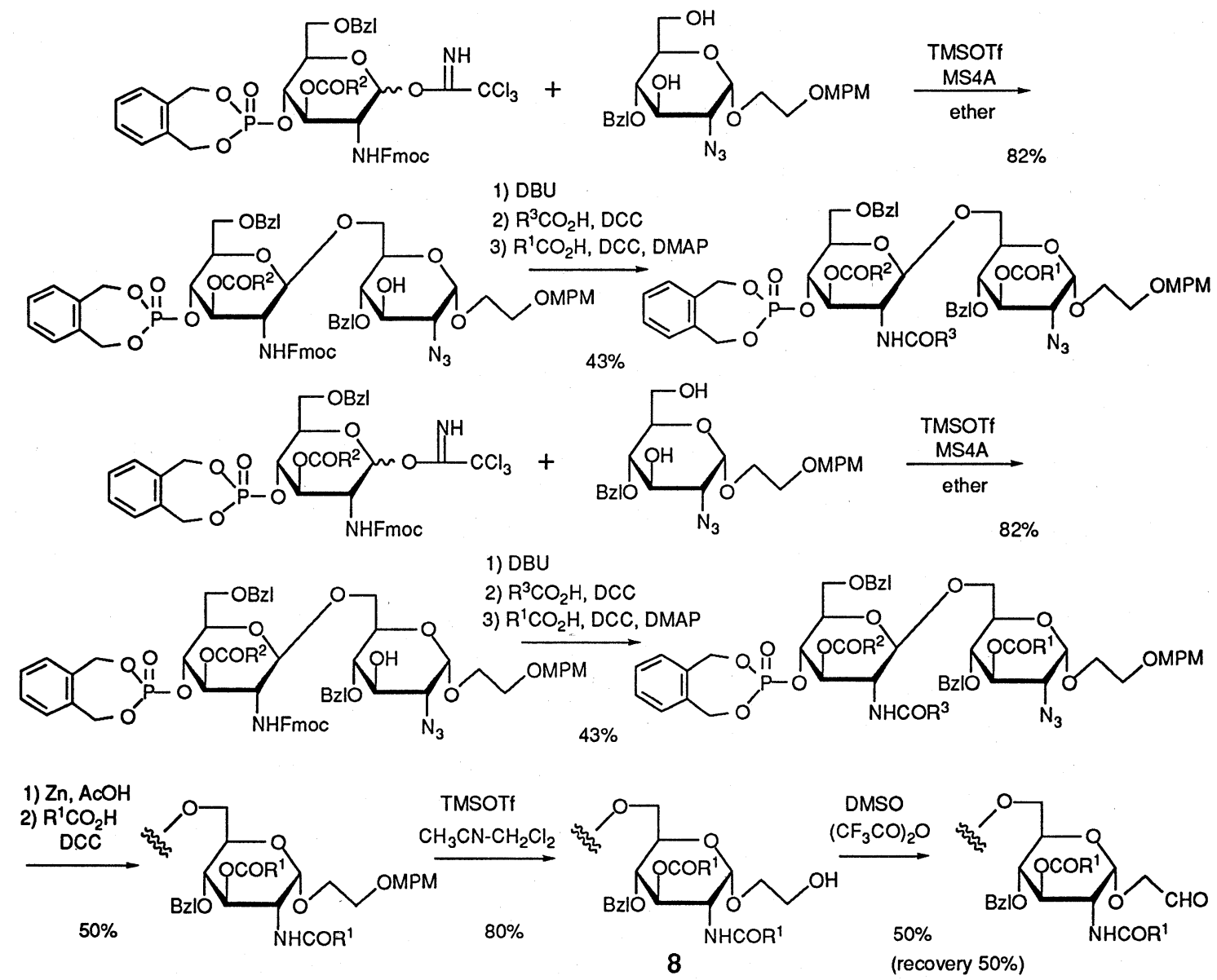

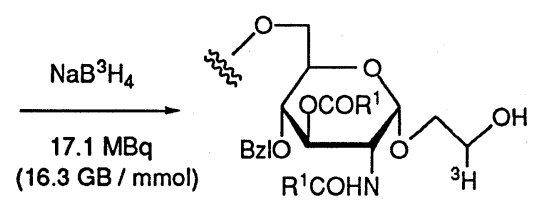

$58 \%$

$9.89 \mathrm{MBq}$
1)<smiles>CCNP1OCc2ccccc2CO1</smiles>

$32 \%$
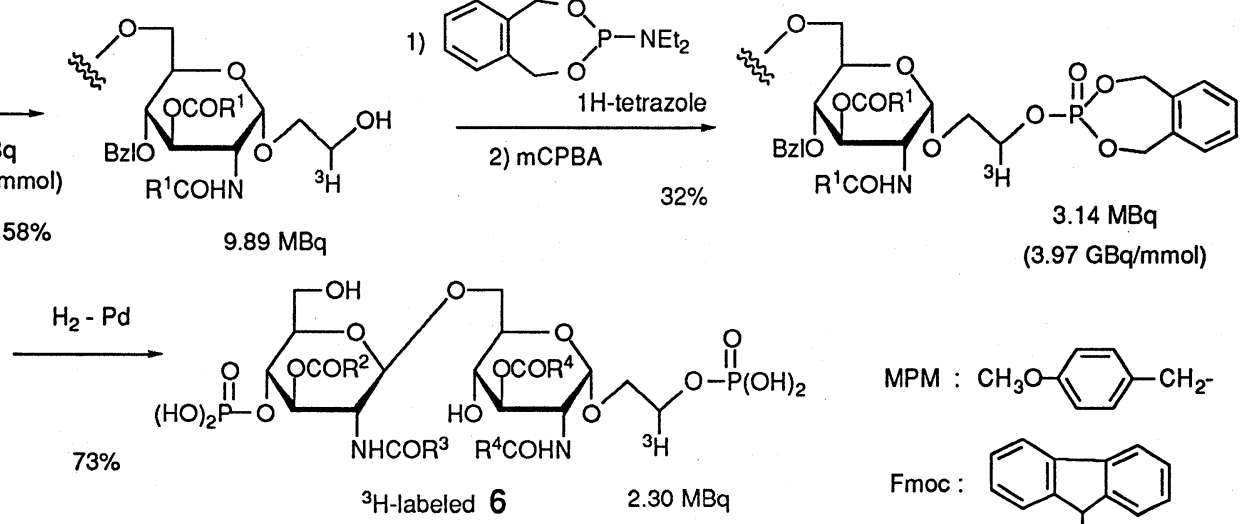

$3.14 \mathrm{MBq}$

( $3.97 \mathrm{GBq} / \mathrm{mmol}$ )<smiles>COc1ccc(CCN(C)C(F)(F)F)cc1</smiles>

(R) (R) (R) $\mathrm{R}^{1} \mathrm{CO}: \mathrm{CH}_{3}\left(\mathrm{CH}_{2}\right)_{10} \mathrm{CH} \mathrm{HCH}_{2} \mathrm{CO}-\mathrm{R}^{2} \mathrm{CO}: \mathrm{CH}_{3}\left(\mathrm{CH}_{2}\right)_{10} \mathrm{CHCH}_{2} \mathrm{CO}-\mathrm{R}^{3} \mathrm{CO}: \mathrm{CH}_{3}\left(\mathrm{CH}_{2}\right)_{10} \mathrm{CHCH}_{2} \mathrm{CO}-\mathrm{R}^{4} \mathrm{CO}: \mathrm{CH}_{3}\left(\mathrm{CH}_{2}\right)_{10} \mathrm{CH} \mathrm{HCH}_{2} \mathrm{CO}$ 


\section{Synthesis of proposed structures of lipoteichoic acid}

\subsection{Occurrence, biological activity and structure of lipoteichoic acid}

Lipoteichoic acid (LTA) is a widely distributed constituent of the cell envelope of Gram-positive bacteria. Distinct antitumor activity was reported for the LTA fractions obtained from Streptococcus pyogenes and Enterococcus hirae (ref. 17). Soon after that, cytokine-inducing activity was also described for the latter LTA (ref. 18). LTA was thus regarded as a new immunostimulating glycoconjugate characteristic of Gram-positive bacteria. Chemical structures of LTAs from both bacteria were proposed as $9 \mathrm{a}$ and 10a by Fischer, who has systematically studied LTAs from various bacteria mainly from the structural point of view without paying much attention to their activity against higher animals (ref. 19). According to him, both LTAs share the general structural principle of LTA consisting of covalently bound glycolipid and hydrophilic poly(glycerol phosphate) (PGP) parts. More precisely, the latter is a (1-3)phosphodiester-linked polymer of glycerol phosphate. The 2-hydroxyl group of the glycerol unit is suggested to be non-stoichiometrically substituted with oligoglucosyl and/or D-alanyl residues. The LTAs of these two bacteria contain a common glycolipid composed of $\alpha(1-2)$ linked disaccharide of glucose and diacyl glycerol. LTA of $E$. hirae contains an additional phosphatidyl unit at the 6-position of the disaccharide.
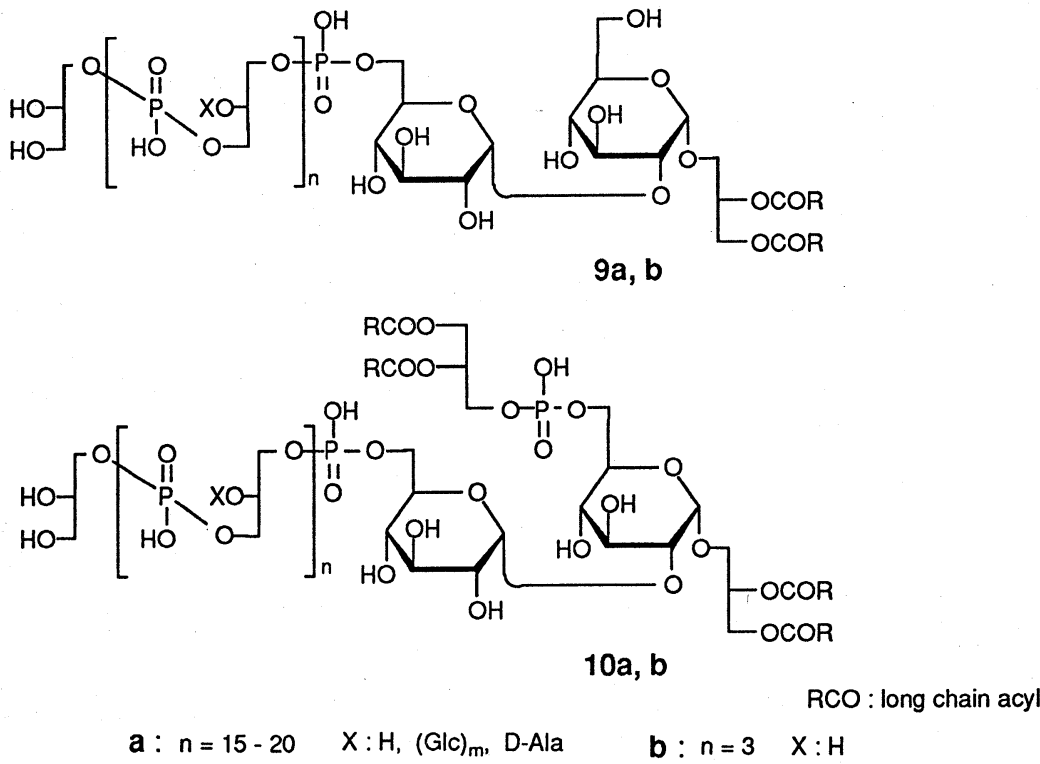

This background prompted us to start the synthesis of the proposed structures in order to prove whether the LTA molecules with these structures are responsible for the activity.

\subsection{Synthesis of the proposed fundamental structures of lipoteichoic acid}

As the initial targets of our synthesis, compounds $9 \mathrm{~b}$ and $10 \mathrm{~b}$ were selected in which the proposed substituents at the glycerol part were eliminated. Our synthetic plan was constructed as follows. The desired LTA structure was completed in its protected form by coupling of the glycolipid and PGP parts which had been prepared separately. After thorough purification of the protected form, all the benzyl-type protecting groups were cleaved in one step to give the final product. This is based on the same strategy as employed in our synthesis of lipid A described above. The major advantage of this strategy is that the purification procedure required for the final amphiphilic product can be minimized. On the other hand, a serious drawback has to be recognized, namely, that compounds containing unsaturated groups can not be prepared in this way. Only palmitic acid was therefore employed in this synthesis though about $50 \%$ of the total fatty acids in natural LTA are known to be unsaturated. 
The PGP part with the proposed stereochemistry was prepared as shown in the scheme by using two types of protecting groups which can be cleaved independently (ref. 20). Thus, two optically pure 2-O-benzyl-glycerol derivatives, 11 and 12, were prepared: the former is protected with the pmethoxybenzyl (MPM) group at the 3-position and the latter with the TBDMS group at the 1-position, respectively. Coupling of these two components by a benzyl-protected phosphorodiamidite reagent 13 followed by m-chloroperbenzoic acid (mCPBA) oxidation gave a glycerol phosphate dimer 14 in a good yield. Treatment of 14 with Bu $4 \mathrm{NF}$ or DDQ gave two products 15 or 16, respectively, which were coupled by the same phosphorodiamidite method to afford the glycerol phosphate tetramer 17. After cleavage of the TBDMS group 17 was converted to the tetramer phosphoroamidite 18 which was to be coupled with the synthetic glycolipid part later.

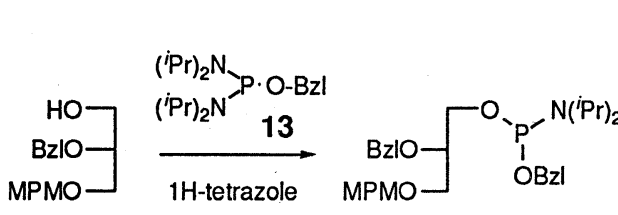

11

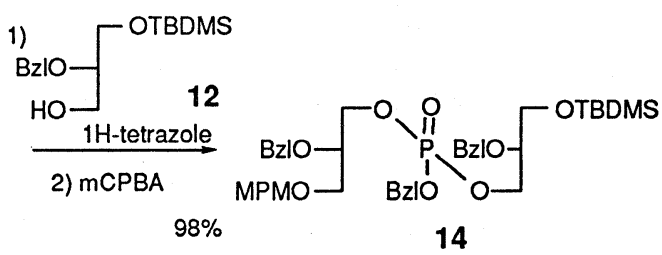

14

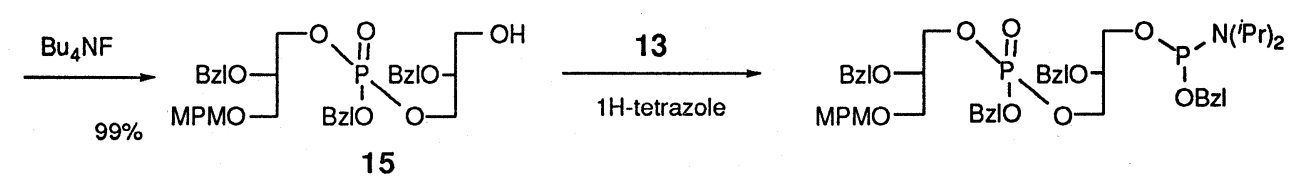

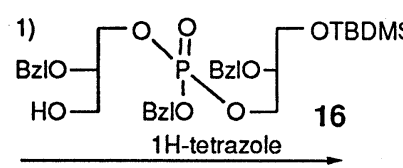

2) $\mathrm{mCPBA}$ $89 \%$

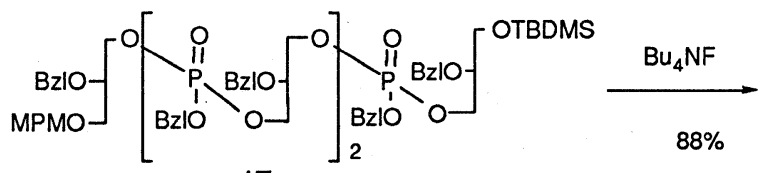

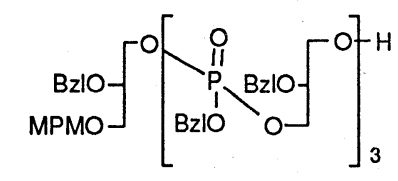

17

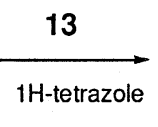

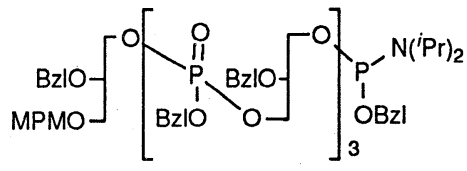

18

For the synthesis of the glycolipid, novel methods for selective cleavage of two p-substituted benzyl groups were utilized. The first one was the p-nitrobenzyl (p-nitrophenylmethyl, NPM) group which is a long-known stable group but was found to be readily cleaved by mild anodic oxidation after reduction to a p-aminobenzyl ether (ref. 22). N-Acylation to the p-acetaminobenzyl ether followed by DDQ oxidation was also a very effective method for the same cleavage. The other was the ppivaloylaminobenzyl (PAB) group, which is stable under reaction conditions for Lewis acid-catalyzed glycosidation and anodic oxidation for the cleavage of the p-aminobenzyl group mentioned above. But the PAB ether can be smoothly cleaved by DDQ oxidation (ref. 23).

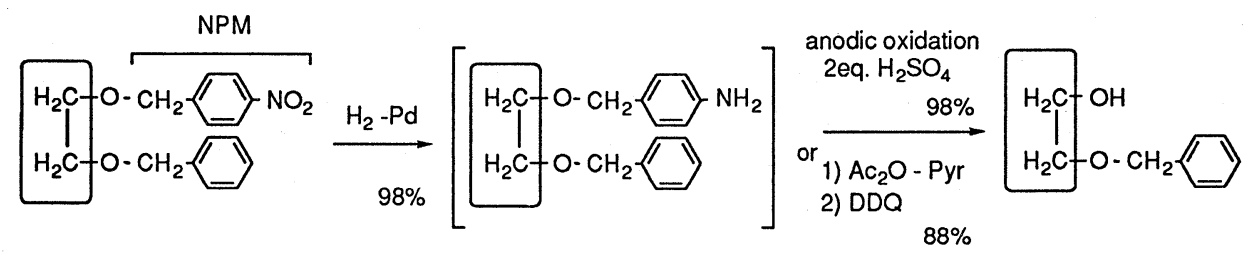




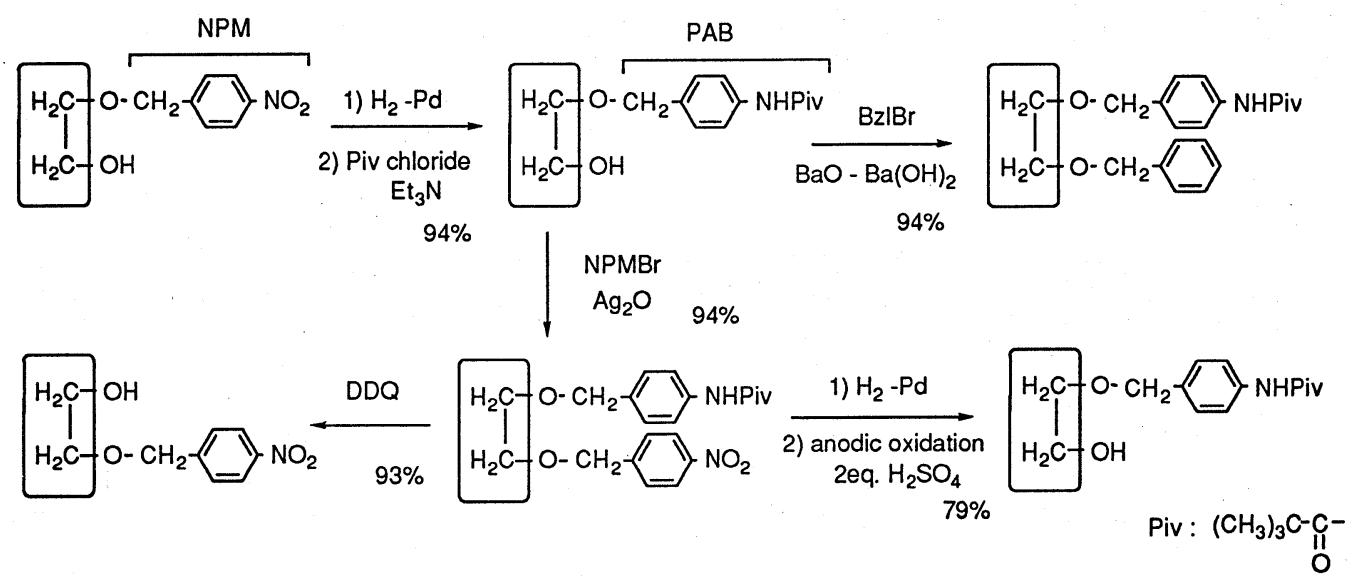

The synthesis of the glycolipid was achieved by stepwise condensation of two glucose units to glycerol. The procedure for the more complex glycolipid of $E$. hirae LTA is illustrated as an example in the scheme (ref. 21). The $\alpha$-glucosyl linkages were formed with glucosyl fluorides having nonparticipating 2-O-protection. Thus, the glucosyl fluoride 19 was prepared whose 2- and 6-hydroxyl groups were protected with NPM and 2,2,2-trichloroethoxycarbonyl (Troc) groups, respectively. The presence of the 6-O-Troc function was found to favor the formation of an $\alpha$-glycosidic linkage (ref. 20, $21,24)$. In order to avoid possible transacylation during the Lewis acid-catalyzed glycosidation step, optically pure diallyl glycerol 20 was used as the acceptor for the glycosilation reaction. Coupling of $\mathbf{1 9}$ and 20 gave the desired $\alpha$-linked product 21 preferentially $(\alpha: \beta=11.5: 1)$, the 6-O-Troc group of which was cleaved and the resultant hydroxyl group protected as a PAB ether. After cleavage of the two allyl groups of 22 and di-O-acylation, the NPM was reduced to the p-aminobenzyl group and then subjected to cleavage by anodic oxidation. The product 23 which retained the intact 6-O-PAB group was coupled with the second glucosyl fluoride 24 to give the $\alpha(1-2)$-linked disaccharide 25 as the major product. The PAB group was then selectively removed by DDQ oxidation to give the free 6-hydroxyl group. Introduction of the phosphatidyl moiety was achieved by the use of the phosphoroamidite 26. The 6'-O-Troc group of 27 was cleaved to give the glycolipid component $\mathbf{2 8}$ to be coupled with the PGP part. The reaction of 18 and $\mathbf{2 8}$ gave the protected fundamental structure of $E$. hirae LTA 29. All the protecting groups of 29 were then removed by catalytic hydrogenolysis to give the target compound 10b, whose structure was confirmed by FABMS [negative mode, m/z $2139.2\left(\mathrm{M}^{-}\right)$]. The corresponding $9 \mathrm{~b}$ was also synthesized via a similar route (ref. 20 ).
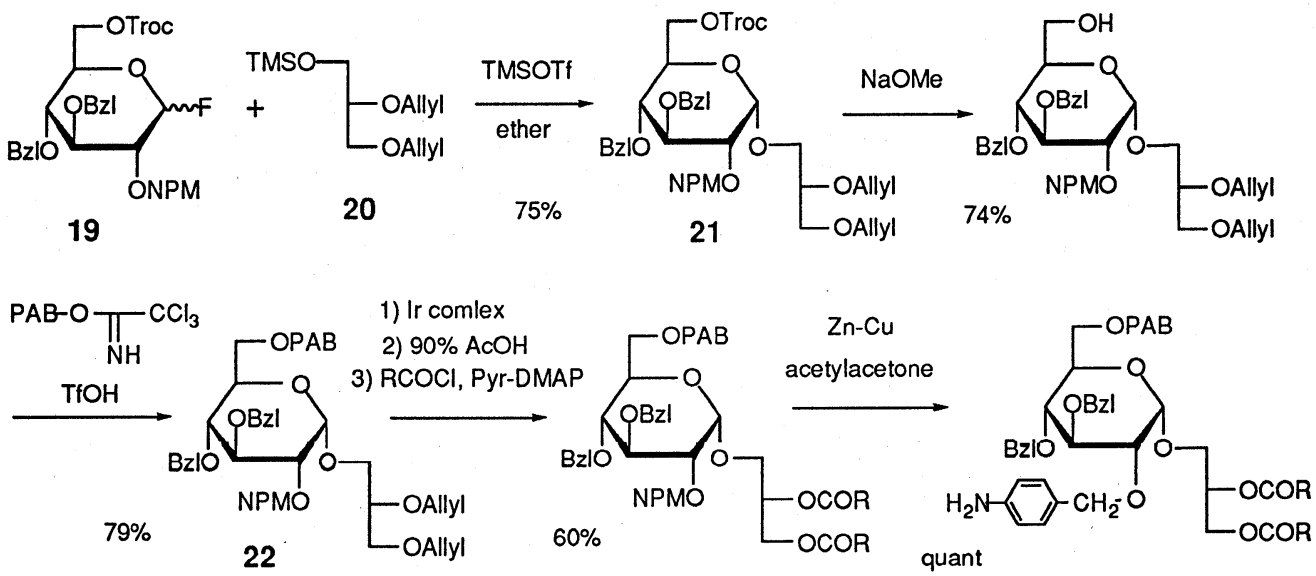

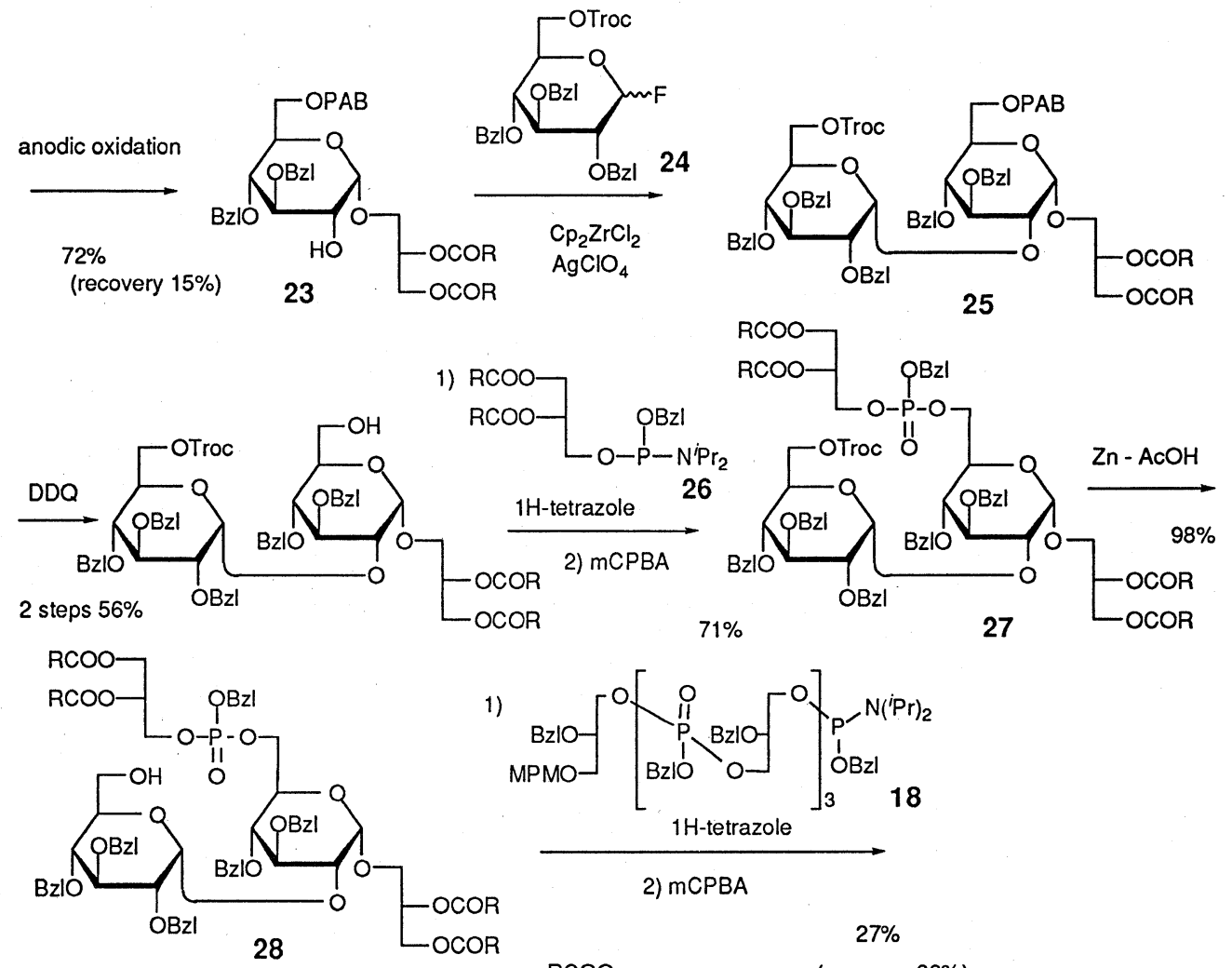

2) $\mathrm{MCPBA}$
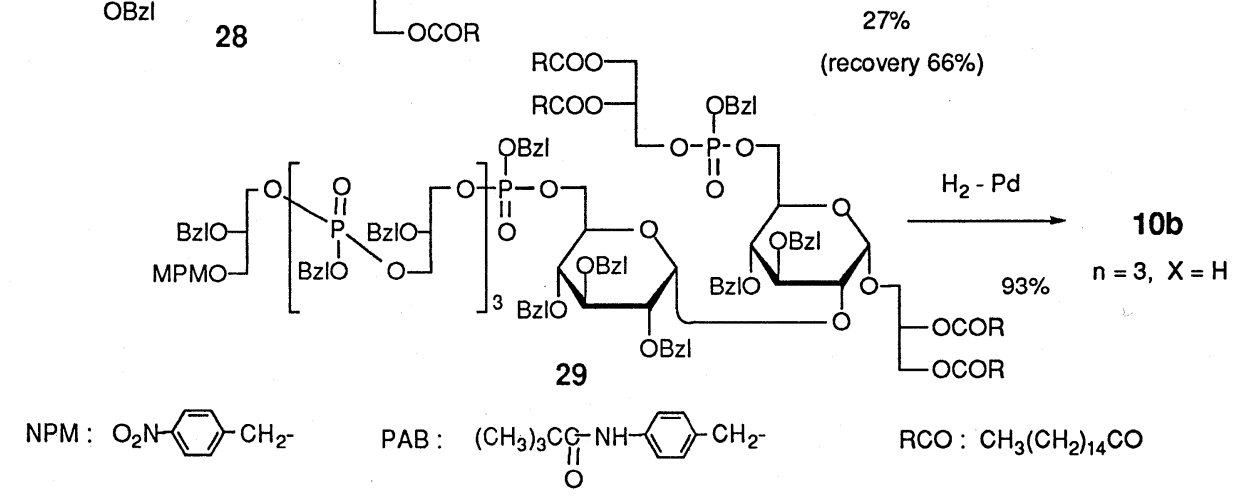

To our surprise, however, the synthetic $9 \mathrm{~b}$ and $10 \mathrm{~b}$ showed none of the expected biological activity observed for the natural LTA fraction. Any of the following three major differences between the synthetic and proposed structures might be responsible for this unexpected result: i) the synthetic structures lack substituents at the glycerol units; ii) unsaturated fatty acids observed in natural LTA are absent in the synthetic compounds; iii) synthetic specimens contain only short PGP chains $(\mathrm{n}=3$ as compared to natural LTA where $n=c a .20)$. But none of these differences were found to be the direct reason as confirmed by our following investigation (ref. 25).

Thus, the so-called LTA obtained from the extract of $E$. hirae cells was subjected to further separation to give two distinct fractions: a major fraction which was retained on the anion exchange resin and a minor one which was not. The latter minor fraction which amounted to only less than $5 \%$ of the total LTA showed distinct cytokine-inducing activity, whereas the major fraction was devoid of such activity (ref. 25). We also found recently that the above proposed structures ( $9 \mathrm{a}$ and 10a) which were the targets of our synthesis correspond to the components of the major inactive fraction (ref. 26). The minor immunostimulating fraction was found to consist of several components, which were separated and are now being studied intensively for their structures in our laboratory. 


\section{Conclusion}

By virtue of recent advances in synthetic chemistry, e.g., efficient methods for glycosidation and sufficient choice of selectively removable protecting groups, complex glycoconjugates have now become yet challenging but accessible targets for organic chemists. The major merit of chemical synthesis in this field is its ability to produce homogeneous and definite compounds, which are particularly important for the determination of the active entities and also for the study of action mechanism. Even in the above apparently disappointing case of LTA, synthesis of the proposed inactive structures provided direct evidence for the presence of the so far unknown true active components and opened a route to their identification.

More detailed and precise investigation on various aspects of biologically active glycosides and glycoconjugates will certainly become possible by further development of organic synthesis.

\section{References and Notes}

(1) Kusumoto, S.; Tarumi, Y.; Ikenaka, K.; Shiba, T. Bull. Chem. Soc. Jpn. 1976, 49, 533 and references therein.

(2) (a) Rietschel, E. Th.; Brade, H. Scientific American, 1992, 267, 54. (b) Rietschel, E. Th.; Brade, L.; Lindner, B.; Zähringer, U. "Bacterial Endotoxic Lipopolysaccharides" Vol. 1, 1992, p. 3, eds Morrison, D. C.; Ryan, J. L. CRC Press.

(3) Imoto, M.; Kusumoto, S.; Shiba, T.; Rietschel, E. Th.; Galanos, C.; Lüderitz, O. Tetrahedron Lett. 1985, 26, 907.

(4) (a) Imoto, M.; Yoshimura, H.; Sakaguchi, N.; Kusumoto, S.; Shiba, T. Tetrahedron Lett. 1985, 26, 1545. (b) Imoto, M.; Yoshimura, H.; Sakaguchi, N.; Kusumoto, S.; Shiba, T. Bull. Chem. Soc. Jpn. 1987, 60, 2205.

(5) (a) Galanos, C.; Lüderitz, O.; Rietschel, E. Th.; Westphal, O.; Brade, H., Brade, L.; Freudenberg. M.; Schade, U.; Imoto, M.; Yoshimura, H.; Kusumoto, S.; Shiba T. Eur. J. Biochem., 1985, 148, 1. (b) Kotani, S.; Tacked, H.; Tsujimoto, M.; Ogawa, T.; Takahashi, I.; Ikeda, T.; Harada, K.; Nagaki, H.; Kitamura, H.; Shiba, T.; Kusumoto, S.; Imoto, M., Yoshimura, H, Infect. Immun., 1985, 49, 225.

(6) (a) Imoto, M.; Yoshimura, H.; Yamamoto, M.; Shimamoto, T.; Kusumoto, S.; Shiba, T. Bull. Chem. Soc. Jpn. 1987, 60, 2197. (b) Kotani, S.; Takada, H.; Takahashi, I.; Tsujimoto, M.; Ogawa, T.; Ikeda, T.; Harada, K.; Okamura, T.; Tamura, S.; Tanaka, T.; Shiba, T.; Kusumoto, S.; Imoto, M.; Yoshimura, H.; Kasai, N. Infect. Immun., 1986, 52, 872. (c) Rietschel, E. Th.; Brade, L.; Schade, U.; Galanos, C.; Freudenberg, M.; Lüderitz, O.; Kusumoto, S.; Shiba, T. Eur. J. Biochem., 1987, 169, 27.

(7) (a) Wang, M.-H.; Feist, W.; Herzbeck, H.; Brade, H.; Kusumoto, S.; Rietschel, E. Th.; Flad, H.D.; Ulmer, A. J. FEMS Microbiol. Immunol., 1990, 64, 179. (b) Wang, M.-H.; Flad, H.-D.; Feist, W.; Musehold, J.; Kusumoto, S.; Brade, H.; Gerdesm, J.; Rietschel, E. Th.; Ulmer, A. J. Infect. Immun., 1992, 11, 23.

(8) Tai, A.; Nakahata, M,; Harada, H,; Izumi, Y.; Kusumoto, S.; Inage, M.; Shiba, T.; Chem. Lett., $1980,1125$.

(9) Oikawa, M.; Kusumoto, S. Tetrahedron: Asymm., 1995, 6, 961.

(10) Fukase, K.; Liu, W.-C.; Suda, Y.; Oikawa, M.; Wada, A.; Mori, S; Ulmer, A. J.; Rietschel, E. Th.; Kusumoto, S. Tetrahedron Lett., 1995, 36, 7455.

(11) Kitamura, M.; Ohkuma, T.; Inoue, S.; Sayo, N.; Kumobayashi, H.; Akutagawa, S.; Ohta, T.; Takaya, H.; Noyori, R. J. Am. Chem. Soc., 1988, 110, 629.

(12) Watanabe, Y.; Komada, Y.; Ebisuya, K.; Ozaki, S. Tetrahedron Lett., 1990, 31, 255.

(13) In our previous synthesis of lipid A (ref. 4,6) the 4'-phosphate was protected as its diphenyl ester. This ester was stable enough but its cleavage required an additional hydrogenolysis step with a platinum catalyst.

(14) Liu, W.-C.; Oikawa. M.; Fukase, K.; Suda, Y.; Hendig, W.; Mori, S.; Hashimoto, M.; Kusumoto, S. Bull. Chem. Soc.Jpn., in press.

(15) (a) Kusama, T.; Soga, T.; Shioya E.; Nakayama, K.; Nakajima, H.; Osada, Y.; Ono, Y.; Kusumoto, S; Shiba, T. Chem. Pharm. Bull., 1990, 38, 3366. (b) Kusama, T.; Soga, T.; Ono, 
Y.; Kumazawa, E.; Shioya E.; Osada, Y.; Kusumoto, S; Shiba, T. Chem. Pharm. Bull., 1991, 39, 1994.

(16) Fukase, K.; Kinoshita, I.; Suda, Y.; Aoki, Y., Liu, W.-C.; Oikawa, M.; Kurosawa, M.; Zähringer, U.; Seydel, U.; Rietschel, E. Th.; Kusumoto, S. Synlett, 1996, 252.

(17) (a) Usami, H; Yamamoto, A.; Yamashita, W.; Sugawara, Y.; Hamada, S.; Yamamoto, T.; Kato, T.; Kokeguchi, S.; Ohkuni, H.; Kotani, S. Br. J. Cancer, 1988, 57, 70. (b) Tsutsui, O.; Kokeguchi, S.; Matsumura, T.; Kato, K. FEMS Microbiol. Immunol., 1991, 76, 211.

(18) Takada, H.; Kawabata, Y.; Arakaki, R.; Kusumoto, S.; Fukase, K.; Suda, Y.; Yoshimura, T.; Kokeguchi, S.; Kato, K.; Komuro, T.; Tanaka, N.; Saito, M.; Yoshida, T.; Sato, K.; Kotani, S. Infect. Immun. 1995, 63, 57.

(19) Fischer, W. "Chemistry and Biological Activities of Bacterial Surface Amphiphiles," 1981, Academic Press, New York, p. 209.

(20) Fukase, K.; Matsumoto, T.; Ito, N.; Yoshimura, T.; Kotani, S., Kusumoto, S. Bull. Chem. Soc. Jpn., 1992, 65, 2643.

(21) Fukase, K.; Yoshimura, T.; Kotani, S., Kusumoto, S. Bull. Chem. Soc. Jpn., 1994, 67, 473.

(22) Fukase, K.; Tanaka, H.; Torii, S.; Kusumoto, S. Tetrahedron Lett., 1990, 31, 389.

(23) Fukase, K.; Yoshimura, T.; Hashida, M.; Kusumoto, S. Tetrahedron Lett., 1991, 32, 4019.

(24) Fukase, K.; Kinoshita, I.; Kanoh, T.; Nakai, Y.; Hasuoka, A.; Kusumoto, S. Tetrahedron, 1996, $52,3897$.

(25) Suda, Y.; Tochio, H.; Kawano, K.; Takada, H.; Yoshida, T.; Kotani, S.; Kusumoto, S. FEMS Immunol. Microbiol., 1995, 12, 97.

(26) Hashimoto, M.; Yasuoka, J.; Suda, Y.; Takada, H.; Yoshida, T.; Kotani S, Kusumoto, S. in preparation.

(Received July 19, 1996) 